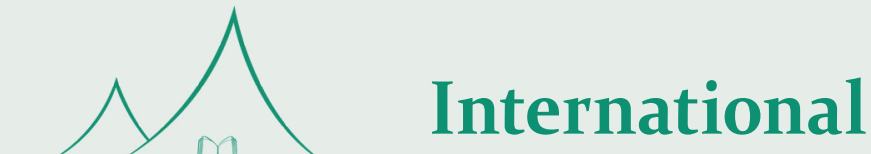 \\ madridge Journal of Material Science and Research \\ Interconnecting Scientific World
}

Research Article

Open Access

\section{The Effect of Chromium Addition on Fluidity, Microstructure and Mechanical Properties of Aluminium LM6 Cast Alloy}

\author{
Ahmad R*
}

Department of Manufacturing and Industrial Engineering, Faculty of Mechanical and

Manufacturing Engineering, Universiti Tun Hussein Onn Malaysia, 86400 Parit Raja, Batu Pahat, Johor, Malaysia

\begin{abstract}
This article investigates the effects of $\mathrm{Cr}$ addition on microstructure, mechanical properties and fluidity of as-cast aluminum (LM6) alloy. Presence of $0.05,0.1$ and 0.15 wt.\% $\mathrm{Cr}$ were add to LM6 melting greensand cast. There is no relationship between $\mathrm{Cr}$ addition and $\mathrm{Si}$ morphology. The $\mathrm{Cr}$ addition had modified the Fe intermetallics to irregular shapes. The mechanical properties such as toughness and hardness of LM6 had increase with increase the $\mathrm{Cr}$ value. The $\beta$-phases have largest surface to volume ratio, hence they have the largest interfacial region with the melt and are the most detrimental intermetallic to the fluidity. The sludge formation and consuming $\mathrm{Si}$ and shifts the local chemical composition of the melt to the aluminum side of the phase diagram increase with $\mathrm{Cr}$ addition, which has lower fluidity than base alloy.
\end{abstract}

Keywords: Aluminum alloys; Microstructure; LM6 alloy; Chromuim; Molten metal.

\section{Introduction}

Aluminum alloys have been the primary material of choice for structural components of aircraft and automobile industry since about 1930. They are the overwhelming choice for the fuselage, wing, and supporting structure for commercial airliners and military cargo and transport due to their high ratio of strength to weight [1]. Aluminum alloy castings are widely used in the automobile and aerospace industries, and are replacing heavier forged steel or cast iron for the lighter and more fuel-efficient automobiles. Producing defect-free Al castings becomes more important. Aluminum alloys are used extensively due to their high strength to weight ratio, good machinability, corrosion resistance, optimum surface finish, and high electrical and thermal conductivity. They are characterized by their low specific gravity, low melting point, negligible gas solubility (with the exception of hydrogen), excellent castability and good corrosion resistance [2, 3]. Alloys containing 10-13 wt. \%Si, eutectic or near eutectic compositions have small freezing range and this alloy system is widely used in automotive applications to produce critical components such as engine blocks, cylinder heads and this group of alloys is sometimes referred to as "piston alloys [3]. The mechanical properties of a casting are controlled by its microstructure which, in turn, is influenced by the chemical composition of the alloy, and by the presence of impurities such as iron, the presence of casting defects (porosity, inclusions, etc). In the case of Al-Si alloys, this would imply the a-Al dendrite arm spacing (DAS), the morphology and size of the eutectic Si particles, and the amount of intermetallics and/or other second-phase constituents present in the microstructure [4]. Chromium is one of elements adding to most of $\mathrm{Al}-\mathrm{Mg}-\mathrm{Si}$ and $\mathrm{Al}-\mathrm{Mg}-\mathrm{Zn}$ groups, in which the amount added generally not exceeding $0.35 \%$ chromium in order to control grain structure, to prevent grain growth in Al-Mg alloys and to prevent recrystallization in Al-Mg-Si 
during heat treatment or hot working [5]. Chromium is known to enhance the corrosion and stress corrosion cracking behaviour of nickel-based alloys in high temperature water. Chromuim can increase the hardness about $8 \%$ of Al-9Si-Cu die cast by addition 0.057 to 0.15 wt.\% [6]. Cr addition also exhibits a similar behavior to that of $\mathrm{Mn}$. The precipitation of the $\alpha$-phase in the form of large dense particles (sludge) in 339 alloys containing relatively high-Cr has been reported by Granger [7]. $\mathrm{Mn}$ and $\mathrm{Cr}$ additions, however, do not significantly reduce the deleterious effect of $\mathrm{Fe}$ on fracture toughness has been reported by Shabestari [8]. The impact toughness of Al-Si alloys is controlled to a significant extent by the morphology and size of the eutectic Si particles, as well as by the size of the $\alpha$-Al dendrites. The size and morphology of the intermetallic phases which form in the interdendritic regions between aluminum and the alloying additives also have a strong influence on the impact toughness of Al-Si [9, 10]. The castability/ fluidity is an important feature since it limits the wall thickness that can be successfully filled. Quantitatively fluidity is determined by measuring the distance of metal flowing through mould channel with small cross section. The spiral test has been extensively used because it is compact and portable, and hence can be used easily in the foundry [11]. Sludge formation not only changes the chemical composition of the molten metal, but also diminishes the castability of molten metal. Sludge formation has been shown to be dependent on the alloy's chemistry, melting and holding temperatures, and time [6]. Gobrecht and Campbell [12] have defined a sludge factor (SF) for Al-Si-Cu alloys. It is useful to determine $\mathrm{Fe}, \mathrm{Mn}$, and $\mathrm{Cr}$ contents to prevent sludge formation. This factor is calculated from the formula shown as Eq.1.

Sludge Factor $(\mathrm{SF})=(1 \times$ wt.\%Fe $)+(2 \times$ wt.\%Mn $)+$

$(3 \times$ wt.\%Cr)

It is obvious that $\mathrm{Cr}$ is the most deleterious element for the formation of sludge and also changing the morphology of intermetallic compounds. The main objective of this research is to investigate the effect of $\mathrm{Cr}$ addition on microstructure, mechanical properties (Impact and Hardness), and fluidity of Al-Si (LM6).

\section{Experimental Produced}

\section{Materials Preparation}

The LM6 alloy ingot with chemical composition illustrated in Table 1 was melted as a base material. Another alloy was prepared, corresponding to additions of $0.05,0.1$ and $0.15 \mathrm{wt} . \% \mathrm{Cr}$ and melted in a SiC crucible in an electrical resistance furnace. After melting the ingots, exact amount of $\mathrm{Cr}$ was added to the melt at $720^{\circ} \mathrm{C}$. A ceramic-coated steel rod stirred the melt for five minutes to ensure the dissolution and homogeneity of $\mathrm{Cr}$ in the melt. The melt temperature was quantified by a K-type thermocouple. The pouring temperature was $670 \circ \mathrm{C}$ into green sand mould.

Table 1. Chemical Composition of LM6 Alloy.

\begin{tabular}{llllllllll}
\hline Elements & $\mathrm{Si}$ & $\mathrm{Cu}$ & $\mathrm{Mg}$ & $\mathrm{Mn}$ & $\mathrm{Fe}$ & $\mathrm{Zn}$ & $\mathrm{Ni}$ & $\mathrm{Ti}$ & $\mathrm{Al}$ \\
$\mathrm{Wt} \%$ & 12.3 & 0.10 & 0.10 & 0.55 & 0.55 & 0.55 & 0.10 & 0.10 & Reminder \\
\hline
\end{tabular}

\section{Microstructure Analysis}

The samples were mounted in resin and grounded with a series of progressively finer $\mathrm{SiC}$ paper size from 250 grit to
4000 grit. Then, the specimens were subjected to a final polishing with Struers Silica OPS suspension $0.5 \mu \mathrm{m}$ until a mirror-smooth surface was obtained. In addition, normal etching with $5 \% \mathrm{HF}$ solution was used to reveal the silicon structure. Scanning electron microscope (SEM/EDS) was used for capture microstructure images and to determine the chemical compositions of intermetallics forming.

\section{Mechanical Properties}

After casting the specimens were machined into desired shape and dimension according to ASTM standard for notched Charpy impact test. In this study, the Charpy impact test was conducted using an impact test machine-Impact Tester MT3016, Wolpert. The geometry and dimension of impact specimen is illustrated in Fig. 1. The reported impact toughness values are the average of four readings for each sample in the present work, extensive Vicker's hardness measurements were conducted to determine the hardness in each alloy. The hardness test specimens were lightly polished using SiC paper. A Vicker's hardness machine tester (Matsuzawa DVK-2) with the applied load of $5 \mathrm{~N}$ had been used for measuring the hardness. The reported hardness values are the average of five readings for each sample.

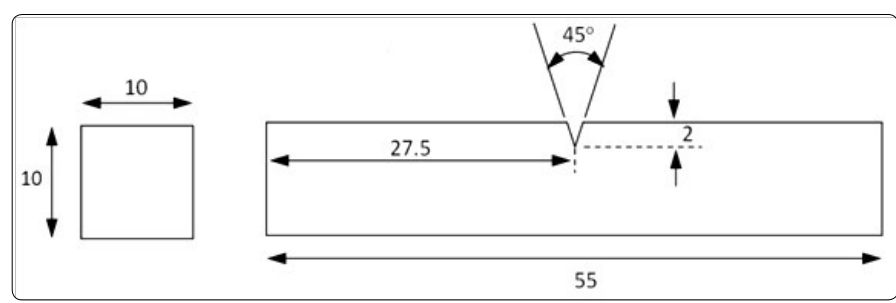

Figure 1. Schematic illustration of Charpy impact specimen (all dimensions in $\mathrm{mm}$ ).

\section{Fluidity test}

The melt (at $670{ }^{\circ} \mathrm{C}$ ) was poured in green sand cast spiral molds. The fluidity measured by the length of flow of the molten metal in the cavity for three castings for each concentration. The fluidity results were measured by the average of three length of metal flow for each alloy.

\section{Results and Discussion}

\section{Microstructure}

It is clear that $\mathrm{Cr}$ addition does not have significant effect on Si morphology as showed in Figure 2, that due to forming phase and modified Fe phase and reduce the quantity [13]. The Si particles display the acicular plate/flake form of the eutectic silicon phase of base alloy and $\mathrm{Cr}$-coning alloy. Similar result was obtained by Timelli and Bonollo [6].
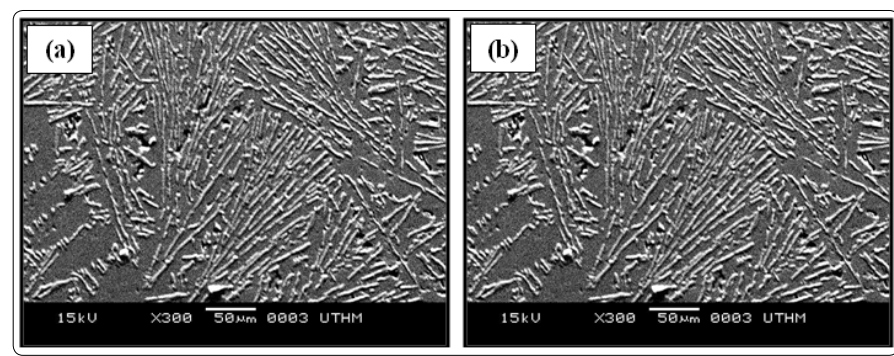

Figure 2. Microstructure images of (a) $0 \mathrm{wt} . \% \mathrm{Cr}$ and (b) $0.15 \mathrm{wt} . \% \mathrm{Cr}$. 
It is well known that $\mathrm{Cr}$ can be added to Al-Si foundry alloys to enhance the high temperature strength of the materials by formation of intermetallic compounds with high thermal stability, such as $\alpha-\mathrm{AlCrSi}, \alpha-\mathrm{Al}(\mathrm{Cr}, \mathrm{Fe}) \mathrm{Si}$, $\alpha-\mathrm{Al}(\mathrm{Fe}, \mathrm{Mn}, \mathrm{Cr}) \mathrm{Si}$ phases [14]. As showed in figure $3 \mathrm{a}$, the $\beta$-AlFeSi intermetallic displayed with Chinese script. Figure $3 \mathrm{~b}$ shows that $\mathrm{Cr}$ addition had formed intermetallic with $\beta$-AlFeSi to Al-Si-Cr-Mn-Fe-Cu and morphology changed into polyhedral and irregular phases. Similar result had obtained with AISi9Cu3 alloy [14].
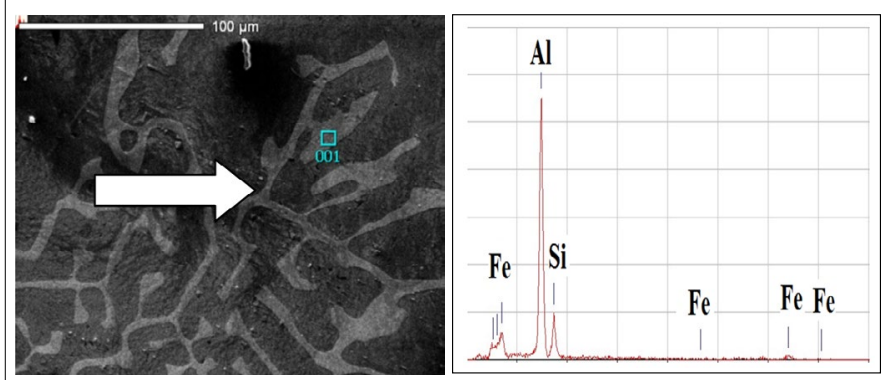

(a)
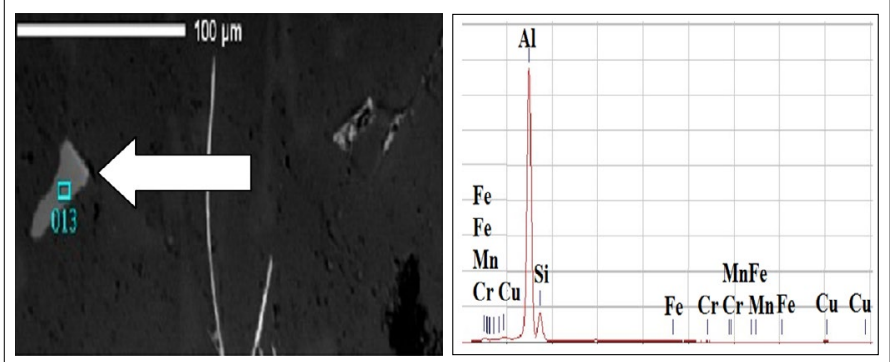

(b)

Figure 3. EDS analysis of (a) $\beta$-AlFeSi and (b) Al-Si-Cr-Mn-Fe-Cu.

\section{Mechanical properties}

There is an obvious increase in impact energy with $\mathrm{Cr}$ addition as showed Figure 4. Figure 4 shows the relation between average absorbed fracture energy and condition of samples in the form of untreated (base alloy $0 \mathrm{wt. \%} \mathrm{Cr}$ ) and treated alloys with concentration of $\mathrm{Cr}$ addition. The base alloy obtained $1.01 \mathrm{~J}$ while the energy increase continuously with increase amount of $\mathrm{Cr}$ addition. As observed, the energy increase to $1.37 \mathrm{~J}$ with $0.05 \mathrm{wt} . \% \mathrm{Cr}$ and continued increase to $1.62 \mathrm{~J}$ and $1.88 \mathrm{~J}$ with 0.1 and $0.15 \mathrm{wt} . \% \mathrm{Cr}$ respectively. This improvement in fracture energy is thanks to modification of intermetallic compounds. According to Shabestari [8], addition of $\mathrm{Cr}$ up to $0.1 \mathrm{wt}$.\% $\mathrm{Cr}$ needed to convert all harmful iron platelet phases, which are usually in needle form, to starlike intermetallics. The sharp tips Fe intermetallics that have needle shape act as stress raisers with a general reduction of the ductility and ultimate tensile strength. On the other hand increasing the $\mathrm{Cr}$ content in the base alloy, the size distribution of the compounds becomes more spread. Therefore, addition of $\mathrm{Cr}$ improves toughness impact by two mechanisms. First eliminating harmful $\beta$-intermetallics and second providing microstructure with more spread particles [14].

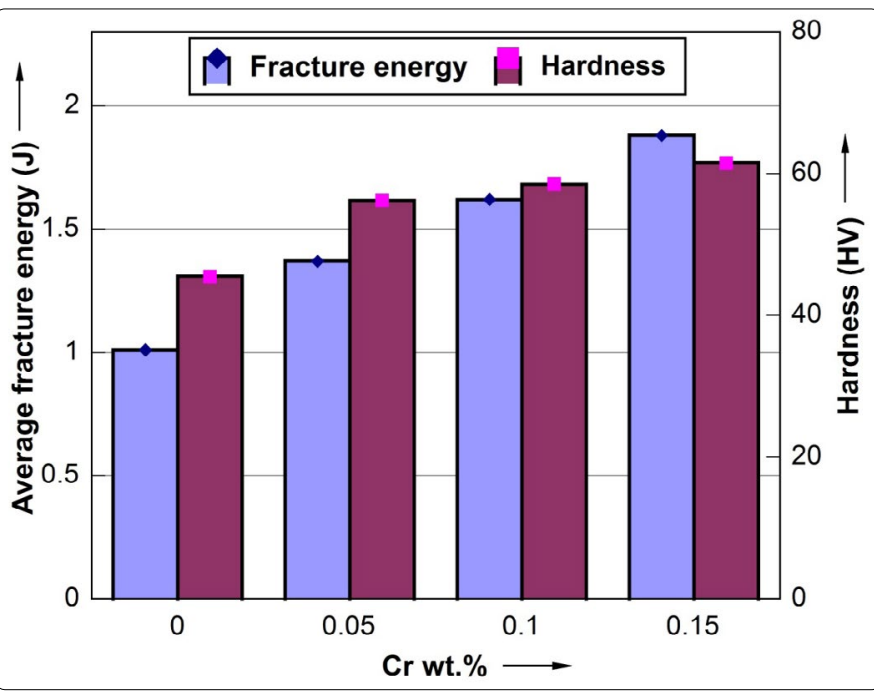

Figure 4. Energy observed of fracture and hardness for base alloy and treated with different $\mathrm{Cr}$ concentration at room temperature

As showed in Figure 4, the value of hardness of LM6 increase with $\mathrm{Cr}$ addition amount increase. The base alloy 0 wt.\% obtained $46 \mathrm{HV}$ and increase to $56 \mathrm{HV}$ with 0.05 wt.\% Cr, while the hardness value slightly increase to 62 with high level of $\mathrm{Cr} 0.15$ wt.\%. This behaviour can be referred to the area fraction of the intermetallics, which increases with the $\mathrm{Cr}$ content $[14,15]$.

\section{Fluidity Test}

The length of fluidity of the aluminum LM6 and additive Chromium are shown in Table 2. In the spiral mold, the length of fluidity is shortened noticeably by presenting of $\mathrm{Cr}$ addition. While the fluidity length of LM6 alloy decreases gradually with increase value of $\mathrm{Cr}$ from $130.45 \mathrm{~cm}$ to $84.5 \mathrm{Cm}$. The main cause of this reduction is formation of sludge. According to segregation factor (SF) equation, sludge formation is dependent on alloy's chemistry and specially $\mathrm{Cr}[16,17]$. The sludge could be precipitate as primary phase and acts as an obstacle for fluidity of molten metal. Segregation factor (SF) is useful to determine $\mathrm{Fe}, \mathrm{Mn}$, and $\mathrm{Cr}$ contents to prevent sludge formation [14]. Cr obviously is the most harmful element for the formation of sludge. According to Eq.1 and chemical composition of the specimens, sludge factor for both base metal (LM6) and the material with $\mathrm{Cr}$ addition is calculated.

Table 2. Length of fluidity in two different wt.\% $\mathrm{Cr}$ concentration.

\begin{tabular}{cc}
\hline $\mathrm{Wt} . \% \mathrm{Cr}$ & Length of fluidity $(\mathrm{cm})$ \\
\hline $0 . \%$ & 130.4 \\
$0.05 . \%$ & 114.1 \\
$0.10 \%$ & 99.2 \\
$0.15 \%$ & 84.5 \\
\hline
\end{tabular}

The fluidity of each alloy as a function of sludge factor is plotted in figure 5. In the Al-Si alloy system $\mathrm{Cr}$ changes the morphology of the intermetallic phase from $\beta$-intermetallics into harmless polyhedral morphology ( $\alpha$-intermetallics). The Sf showd significant effect on fluidity of base alloy, while increase $\mathrm{Cr}$ addition will lead to increase the Sf that had reduction fluidity. Sludge factor (Sf) inversely proportional with fluidity length, the base alloy had obtained lower Sf 1.65 and fluidity length $130.45 \mathrm{~cm}$ and continued decrease length 
with increase the $\mathrm{Sf}$ as showed with high amount of $\mathrm{Cr} 0.15$ wt.\% with $2.1 \mathrm{Sf}$ and $84.5 \mathrm{Cm}$ fluidity length. The fluidity of the melt is affected by both the morphology and volume percentage of intermetallics. The $\beta$-phases have largest surface to volume ratio, hence they have the largest interfacial region with the melt and are the most detrimental intermetallic to drop off the fluidity. In $\mathrm{Cr}$-containing alloys the effect of $\alpha$-phase is less detrimental than $\beta$-phase to the fluidity [17].

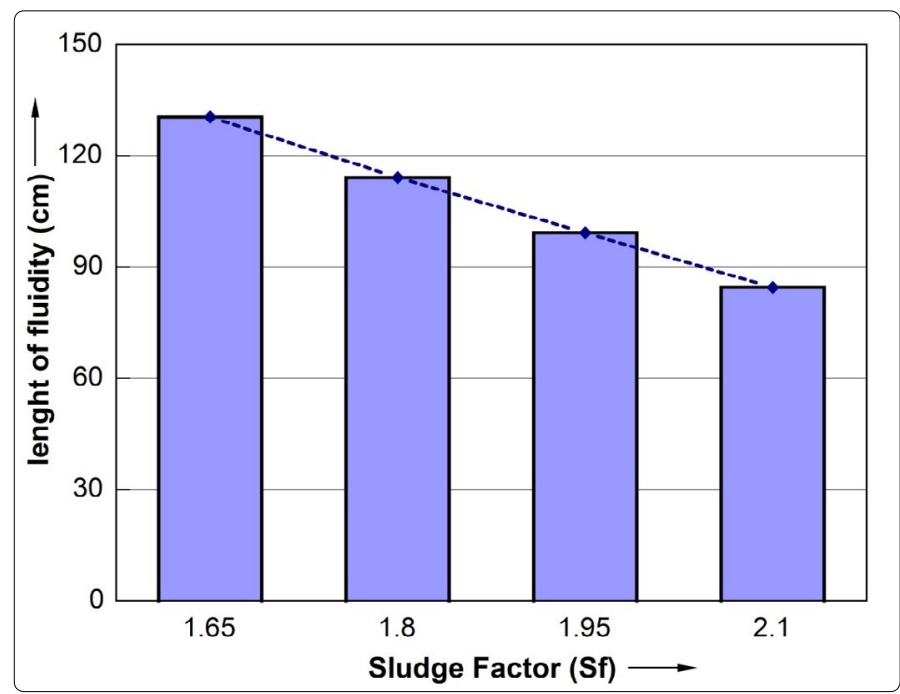

Figure 5. The fluidity of each alloy as a function of sludge factor

\section{Conclusion}

The effect of $\mathrm{Cr}$ addition on the mechanical properties, microstructure and fluidity of aluminum (LM6) alloy has been investigated. Based on results obtained in the present study, addition of $\mathrm{Cr}$ has increased the amount of impact toughness in the aluminum (LM6) alloys. The mechanisms of this increase in fracture energy are listed below:

The $\mathrm{Cr}$ addition has forming compound with $\beta$ (AlFeSi) into a block-shaped Al-Si-Mn-Cr-Fe-Cu phase, which improves the morphology of the Fe phase.

Therefore, addition of $\mathrm{Cr}$ improves mechanical properties such as toughness impact and hardness that increase by $46.8 \%$ of toughness and $37.9 \%$ of hardness.

Increasing inclusions or primary intermetallics in the melt decreases the critical solid fraction at the flow tip and hence, reduces flow time and fluidity length.

\section{References}

1. Jain S. Corrosion and protection of heterogeneous cast Al-Si (356) and Al-Si-Cu-Fe (380) alloys by chromate and cerium inhibitors. The Ohio State University. 2006.

2. Kaufman JG, Rooy EL. Aluminum Alloy Castings. Properties Processes and Applications. ASM International, Materials Park. 2004.

3. Cole G, Sherman A. Light weight materials for automotive applications. Materials characterization. 1995; 35: 3-9. doi: 10.1016/1044-5803(95)00063-1

4. Mondolfo LF. Aluminum alloys: structure and properties. Butterworths London. 1976. doi: 10.12691/msme-4-1-2

5. Hatch JE, Association A. Aluminum: properties and physical metallurgy. ASM International. 1984.

6. Timelli $\mathrm{G}$, Bonollo $\mathrm{F}$. The influence of $\mathrm{Cr}$ content on the microstructure and mechanical properties of AlSi9Cu3(Fe) die-casting alloys. Materials Science and Engineering. A. 2010; 528: 273-82. doi: 10.1016/j.msea.2010.08.079

7. Shabel BS, Granger DA, Truckner WG. Friction and wear of aluminum-silicon alloys. ASM Handbook. 1992; 18: 785-94. doi: 10.1361/asmhba0002331

8. Shabestari $\mathrm{S}$. The effect of iron and manganese on the formation of intermetallic compounds in aluminum-silicon alloys. Materials Science and Engineering: A. 2004; 383: 289-98. doi: 10.1016/j.msea.2004.06.022

9. Elsebaie O, Samuel AM, Samuel F, Doty H. Impact toughness of Al-Si-Cu$\mathrm{Mg}$-Fe cast alloys: Effects of minor additives and aging conditions. Materials \& Design. 2014; 60: 496-509. doi: 10.1016/j.matdes.2014.04.031

10. Ahmad R, Asmael M, Ourdjini A. Effect of High Cerium and Lanthanum on Impact Toughness of Al-11Si-Cu Eutectic Cast Alloy. Applied Mechanics and Materials. 2014; 660:195-98. doi: 10.4028/www.scientific.net/ AMM.660.195

11. Asmael $M$, Ahmad R, Ourdjini A. Effect of Mish Metal Cerium Addition on Fluidity of Aluminum Eutectic Silica Alloys-LM6. Applied Mechanics and Materials. 2014; 465:839-42. doi: 10.4028/www.scientific.net/AMM.465466.839

12. Cao $X$, Campbell J. The solidification characteristics of Fe-rich intermetallics in Al-11.5 Si-0.4 Mg cast alloys. Metallurgical and Materials Transactions A. 2004; 35: $1425-35$

13. Hu P, Su Y, Chen WP, Jiang Y. Effects of $\mathrm{Ce}, \mathrm{Mn}, \mathrm{Cr}$ on the Microstructure and Properties of High-Iron Eutectic Al-Si Piston Alloy. Advanced Materials Research: Trans Tech Publ. 2013; 652: 1023-29. doi: 10.4028/www. scientific.net/AMR.652-654.1023

14. Timelli G, Fabrizi A, Capuzzi S, Bonollo F, Ferraro S. The role of $\mathrm{Cr}$ additions and Fe-rich compounds on microstructural features and impact toughness of AlSigCu3 (Fe) diecasting alloys. Materials Science and Engineering: $A$. 2014; 603: 58-68. doi: 10.1016/j.msea.2014.02.071

15. Apelian D, Makhlouf M. Casting Characteristics of Aluminum Die Casting Alloys. Report Performed Under DOE Contract Number DEFC0799ID13716200246. 2002.

16. Pacz Aladar.US Patent No 1387900.

17. Davis JR, Davis JR. Aluminum and aluminum alloys. ASM international.1993. 